\title{
Management of asthma exacerbations in children
}

\author{
S Kling, ${ }^{1}$ FCPaed (SA), MMed (Paed), MPhil (Applied Ethics); \\ D A White, ${ }^{2}$ MB BCh, FCPaed (SA), MMed (Paed), Dip Allerg (SA), Cert Pulmonology (SA) Paed

\begin{abstract}
${ }^{1}$ Department of Paediatrics and Child Health, Faculty of Medicine and Health Sciences, Stellenbosch University, Cape Town, South Africa
${ }^{2}$ Charlotte Maxeke Johannesburg Academic Hospital and Department of Paediatrics and Child Health, Faculty of Health Sciences,
\end{abstract} \\ University of the Witwatersrand, Johannesburg, South Africa
}

Corresponding author S Kling (sk@sun.ac.za)

\begin{abstract}
Asthma exacerbations are episodes of worsening asthma symptoms with shortness of breath, cough, wheeze and/or tight chest that require an increase in asthma treatment. A major change in the recommendations for managing mild asthma exacerbations is the move away from using inhaled short-acting beta-2 agonists (SABAs) as the sole reliever, toward a combination of a rapid-onset, long-acting beta-2 agonist, formoterol, in combination with an inhaled corticosteroid (ICS), or a SABA used together with an ICS in separate inhalers, in older children and adolescents. In children $<11$ years of age who are adherent to daily ICS treatment, the ICS dose should not be increased short term. A written asthma plan should include instructions on how to self-manage asthma exacerbations, and when to present to a medical facility. Oxygen is an essential component of the management of asthma exacerbations at both primary care and emergency department facilities, together with inhaled SABAs via metered-dose inhaler and spacer, and oral corticosteroids.
\end{abstract}

S Afr Med J 2021;111(8):710-713. https://doi.org/10.7196/SAMJ.2021.v111i5.15853

Asthma exacerbations are episodes of worsening asthma symptoms, namely shortness of breath, cough, wheeze and/or tight chest that require an increase in asthma treatment. ${ }^{[1]}$ Exacerbations usually occur in children who are known to have asthma, but occasionally they may herald the onset of asthma. ${ }^{[1]}$ The term 'flare-up' is useful in discussions with patients.

\section{Triggers of asthma exacerbations}

Common triggers of asthma exacerbations are viral upper respiratory tract infections (commonly rhinovirus infections), allergen exposure (including aero-allergens and foods), pollution or poor adherence to controller medication, but exacerbations may occur without any obvious precipitating factors. It is also recognised that severe asthma exacerbations may occur in patients with mild asthma or well-controlled asthma symptoms. In fact, the recent changes in the strategy for managing 'mild' asthma have occurred as a result of evidence that patients with mild asthma are at risk of severe exacerbations and increased mortality. ${ }^{[1-3]}$

\section{Prevention of asthma exacerbations}

The four pillars of asthma management are: patient and caregiver education; symptom monitoring; avoidance of triggers and control of comorbidities; and pharmacological therapy. Attention to all of these factors are integral to the prevention of asthma exacerbations. ${ }^{[4]}$

\section{Diagnosis of asthma exacerbations}

Although exacerbations present with worsening asthma symptoms, this is not a reliable indication of the severity of the exacerbation. It is important to remember that some asthmatics may have a poor perception of worsening airflow obstruction, ${ }^{[5]}$ therefore lung function tests (peak expiratory flow (PEF) or forced expiratory volume in 1 second $\left(\mathrm{FEV}_{1}\right)$ ) provide an objective indication of the degree of airflow limitation. Lung function tests can be performed in children $>5$ years of age, although they may struggle in the context of an acute asthma exacerbation if they are not used to performing them.

\section{Changes in strategy for the management of mild asthma}

Until 2019, asthma guidelines recommended as-needed short-acting beta-2-agonists (SABA) at step 1, i.e. for mild intermittent asthma. Safety concerns around the increased risk of mortality associated with overuse of SABA, as well as evidence that patients with mild asthma are at risk of severe exacerbations and increased mortality, prompted a revision of the recommendations. ${ }^{[2,3]}$

According to the current strategy recommended by the Global Initiative for Asthma (GINA), the preferred option for step 1 treatment for mild asthma exacerbations in adults and adolescents is an inhaled corticosteroid (ICS) combined with formoterol, a rapidonset long-acting beta-2-agonist (LABA) (budesonide-formoterol), used as needed. If this is not available, an ICS can be used together with a SABA as needed. ${ }^{[2]}$ This recommendation was based on two studies, SYGMA 1 and SYGMA 2, which found that regular twicedaily ICS (budesonide) was superior to the budesonide-formoterol combination with which it was compared, but the latter resulted in lower corticosteroid exposure. ${ }^{[6,7]}$ The GINA committee did not recommend regular ICS at step 1 because it was considered extremely unlikely that patients with such infrequent symptoms would be prepared to take a daily treatment. ${ }^{[}[8]$

In children aged 6 - 11 years, the recommendation from GINA is for as-needed ICS together with a SABA, or regular ICS with as-needed SABA. ${ }^{[2]}$

A recently published report from the Expert Panel Working Group of the US National Heart, Lung, and Blood Institute (NHLBI)administered and co-ordinated National Asthma Education and Prevention Program Coordinating Committee (NAEPPCC) addressed aspects of the asthma management guidelines. ${ }^{[9]}$ The expert panel conditionally recommended either daily low-dose ICS and as-needed SABA for quick-relief treatment, or as-needed ICS and SABA used together in individuals aged $\geq 12$ years, and daily low-dose ICS and as-needed SABA in children aged 5 - 11 years who have mild persistent asthma. In children with moderate to severe persistent asthma, the NAEPPCC 2020 update recommends daily 
and as-needed ICS-formoterol in a single inhaler as a step 3 option in all children aged $>5$ years. The panel recommended against a shortterm increase in the ICS dose for worsening symptoms in children $<11$ years of age, if the child is adherent to daily ICS treatment, with the concern being steroid side-effects. ${ }^{[9]}$

The expert panel addressed the definition of intermittent ICS dosing as follows: "Intermittent" ICS dosing in this section includes courses of ICS treatment used for brief periods, usually in response to symptoms or as an add-on with or without a LABA. "Intermittent ICS dosing" does not refer to a single regimen ... Intermittent ICS dosing allows providers to prescribe specific doses, frequencies, and durations of ICS use. When to use intermittent ICS dosing could depend on an individual's decision (based on need, which is also known as "as-needed" or "pro re nata" dosing), a predefined index showing worsening asthma, or some other predefined criterion. ${ }^{[9]}$ The expert panel also recommended that the ICS-formoterol should preferably be in a single inhaler. ${ }^{[9]}$

The strategy of the as-needed ICS-formoterol combination for South Africa raises the following concerns: the only formoterolcontaining combination inhaler available is budesonide-formoterol; the combination inhaler has limited availability in the public health sector; the inhaler is costly; and using it as intermittent or as-needed treatment constitutes off-label use. As-needed ICS and SABA in separate inhalers also constitutes off-label use, but it is readily available and more affordable. Another concern regarding as-needed use of any therapy is the poor perception that many asthmatics have regarding their own worsening airway obstruction. ${ }^{[10]}$

\section{Management of asthma exacerbations Self-management}

Self-management of asthma exacerbations requires a written asthma action plan. This should include the following:

- monitoring of symptoms and/or lung function

- details of the personalised changes in reliever and controller medication

- when and how to use oral corticosteroids (OCS)

- when and how to present to a healthcare facility, including emergency contact numbers.

The current recommendations are to use an ICS whenever inhaled reliever medication is taken. ${ }^{[1,8]}$

Patients on as-needed low-dose budesonide-formoterol should increase their dose of medication by 1 - 2 puffs as-needed budesonideformoterol up to a maximum total daily maintenance and rescue dose of $72 \mathrm{mcg}$ in adolescents and adults ${ }^{[1]}$ and $36 \mathrm{mcg}$ in children aged 5 - 11 years. ${ }^{[9]}$ This strategy should not be advised for patients taking other combined ICS-LABA controller therapies with slow onset LABAs (such as fluticasone-salmeterol). For patients on maintenance ICS alone, studies in adolescents and adults have shown that a short-term increase in the dose of ICS might help to prevent the progression of asthma to a more severe exacerbation, but this effect may be greater in patients with suboptimal adherence. ${ }^{[1]]}$ However, this is not recommended for children $<11$ years old. ${ }^{[9]}$ Patients who use a SABA as their reliever medication should be instructed to use this at increased doses until symptomatic relief is achieved, or until an increase in their controller treatment works. The SABA dose is 2 10 puffs via a pressurised metered-dose inhaler (pMDI) and spacer taken 30 minutes apart. Lack of response is an indication to present to a primary care clinic or practitioner, as oxygen therapy may be required. ${ }^{[1]}$

The written asthma action plan should include instructions regarding when to use OCS and what dose to use. The dose of prednisone for children and adolescents aged $>11$ years is $40-50 \mathrm{mg}$ daily for 5 - 7 days, and for children aged 6 - 11 years, $1-2 \mathrm{mg} / \mathrm{kg} /$ day to a maximum of $40 \mathrm{mg} /$ day for $3-5$ days. Indications for OCS are: failure to respond to increased controller and reliever medication for 2 - 3 days; rapid deterioration; and history of severe asthma exacerbations. ${ }^{[1]}$

Patients who manage their exacerbations at home should have a follow-up review by their primary care health professional within 1 - 2 weeks. ${ }^{[1]}$

\section{Management of asthma exacerbations in primary care}

A brief history and appropriately focused physical examination should be done at the same time as commencement of treatment. Mild exacerbations can be treated at primary care level, but for severe or life-threatening exacerbations the patient must be transferred to an acute care hospital after commencing SABA, oxygen and systemic corticosteroids. Pulse oximetry should be available in all primary care facilities. Oxygen saturation levels $<92 \%$ are an indication of a severe asthma exacerbation. ${ }^{[12-14]}$

The main initial therapy for an asthma exacerbation is repeated doses of inhaled SABA, OCS and oxygen via nasal cannulae. Mild to moderate exacerbations can be treated with repeated doses of SABA via pMDI and spacer combination ( 4 - 10 puffs every 20 minutes for the first hour). Subsequent treatment varies from $6-10$ puffs every 1 - 2 hours to 4 - 10 puffs every 3 - 4 hours if there is an improvement. If the response to the initial SABA treatment is good, no additional SABA treatment is required. ${ }^{[1]}$

Oxygen should be administered to keep oxygen saturation between 93 and 95\% for adolescents and older children, and $94-98 \%$ for children aged $6-11$ years. ${ }^{[14]}$ OCS at $1-2 \mathrm{mg} / \mathrm{kg} /$ day up to $40 \mathrm{mg} /$ day of prednisolone or prednisone should be given for $3-5$ days. ${ }^{[15]}$

Regular review of the response to therapy should be undertaken. Deterioration or failure to respond necessitates referral to an acute care hospital. Follow-up at primary care level should occur between 1 and 2 weeks after discharge. ${ }^{[1]}$

\section{Management of asthma exacerbations in the emergency department (ED)}

A brief history and appropriately focused physical examination should be done at the same time as treatment is commenced. An assessment of severity should be performed urgently, and features suggesting a life-threatening exacerbation (Table 1) ${ }^{[16,17]}$ necessitate referral to a facility with a paediatric intensive care unit after initial stabilisation. Objective measurements include oxygen saturation by pulse oximetry. Saturation $<92 \%$ correlates with the likelihood of hospitalisation. If possible, PEF measurement should be done. Routine chest X-rays are not recommended. Arterial blood gas measurements should be considered in patients with a poor response to initial therapy, those who are deteriorating or those whose $\mathrm{PEF}$ is $<50 \%$ expected. $\mathrm{PaO}_{2}<60 \mathrm{mmHg}(8 \mathrm{kPa}$ ) and increased $\mathrm{PaCO}_{2}>45 \mathrm{mmHg}(6 \mathrm{kPa})$ indicate respiratory failure.

Treatment consists of oxygen via nasal cannula or mask to achieve saturations of $93-95 \%$ in older and $94-98 \%$ in younger children. ${ }^{[1]}$ Oxygen therapy should be titrated according to the patient's response. ${ }^{[18-21]}$ Repeated doses of inhaled SABA should be administered, preferably via pMDI with a spacer (as above), except in life-threatening acute asthma, when an oxygen-driven nebuliser should be used. Delivery of inhaled bronchodilators by pMDI with valved chamber and mask together with oxygen by nasal cannula separately has been shown to be more effective than by a nebuliser in severe acute asthma exacerbations. ${ }^{[22]}$ An additional concern regarding nebuliser use is its potential to disseminate aerosols and therefore, potentially, viral infections. ${ }^{[23]}$ This is of particular concern 


\begin{tabular}{|c|c|}
\hline \multirow[t]{5}{*}{ Life-threatening asthma } & Silent chest; poor respiratory effort \\
\hline & Cyanosis; $\mathrm{SpO}_{2}<90 \%$ \\
\hline & Bradycardia, dysrhythmia or hypotension \\
\hline & Exhaustion, confusion or drowsiness \\
\hline & PEFR $<33 \%$ predicted \\
\hline \multirow[t]{8}{*}{ Severe asthma exacerbation } & $\mathrm{SpO}_{2}<90 \%$ \\
\hline & Unable to complete sentences in one breath; too breathless to talk or feed \\
\hline & Agitation \\
\hline & Accessory muscle use during expiration \\
\hline & Tachycardia $^{*}$ \\
\hline & Tachypnoea $^{\dagger}$ \\
\hline & PEFR $<50 \%$ predicted or unable to perform PEFR measurements owing to fatigue \\
\hline & Previous ICU admission \\
\hline \multirow[t]{5}{*}{ Moderate asthma exacerbation } & Able to talk in sentences \\
\hline & Pulse rate within normal limits \\
\hline & Respiratory rate within normal limits \\
\hline & $\mathrm{SpO}_{2} \geq 92 \%$ \\
\hline & PEFR $\geq 50 \%$ predicted \\
\hline
\end{tabular}

\section{Table 2. Management at discharge}

\begin{tabular}{ll}
\hline Inhalers & Check technique \\
& Stress adherence \\
& Add spacer device \\
Reliever & Continue as needed \\
& SABA-only treatment of asthma not recommended \\
Controller & Start regular ICS (occurrence of a severe exacerbation is a risk factor for future \\
& exacerbations) \\
& OR step up current treatment \\
OCS & 3 - 5 days \\
Modifiable risk factors & Avoid allergen exposure, pollution, smoking \\
Comorbidities & Manage allergic rhinitis, food allergy \\
Written action plan & Is it understood? Does it need adjustment? \\
Follow-up & Within 1 - 2 weeks \\
SABA = short-acting beta-2 agonist; ICS = inhaled corticosteroids; OCS = oral corticosteroids.
\end{tabular}

during the COVID-19 pandemic. ${ }^{[16]}$ Routine use of intravenous beta2-agonists is not recommended. ${ }^{[1]}$

Systemic corticosteroids should be administered early in asthma exacerbations managed in the $\mathrm{ED}$, except in the very mildest cases. This should preferably be done within the first hour after presentation, as OCS take approximately 4 hours to take effect. Oral administration is as effective as intravenous corticosteroids. The dose is $1-2 \mathrm{mg} / \mathrm{kg} /$ day up to $40 \mathrm{mg} /$ day of prednisolone or prednisone for 3 - 5 days. ${ }^{[15]}$

Ipratropium bromide added to SABA in the treatment of moderatesevere asthma exacerbations in the ED has been shown to reduce the need for hospitalisation and to improve lung function. ${ }^{[24-27]}$ Intravenous magnesium sulphate (a single dose of $50 \mathrm{mg} / \mathrm{kg}$ magnesium sulphate up to a maximum dose of $2 \mathrm{~g}$ over 20 minutes) may be used in children who do not respond to the initial management and who have persistent hypoxaemia. ${ }^{[27-29]}$ There is no evidence to support the use of nebulised magnesium sulphate in the treatment of asthma exacerbations. ${ }^{[27,30]}$ Limited evidence exists for the use of leukotriene receptor antagonists in acute asthma. ${ }^{[27,31]}$ Intravenous aminophylline should not be used in the ED. Antibiotics should not be used routinely. ${ }^{[1]}$
Regular reassessment and review of the response to treatment is essential, with the treatment adjusted according to the response. Poor response to therapy is an indication for admission, and deterioration is an indication for referral to the intensive care unit.

The patient can be assessed for discharge once the symptoms have improved, the patient no longer needs SABA, oxygen saturation is $>94 \%$ in room air, PEF is $>60-80 \%$ expected, the child can eat or drink normally and resources at home are adequate. Management at discharge is summarised in Table 2.

A follow-up appointment with the patient's primary care health professional should be scheduled 1 - 2 weeks after discharge from the ED.

\section{Conclusion}

Notwithstanding attention to avoidance of triggers and regular pharmacotherapy, asthma exacerbations occur, with more frequent exacerbations occurring in patients who have severe disease. ${ }^{[4]}$ It is important to recognise worsening asthma control and intervene early, with inhaled SABA bronchodilators and systemic corticosteroids providing the mainstay of therapy for exacerbations. 


\section{Declaration. None.}

Acknowledgements. None.

Author contributions. Equal contributions.

Funding. None.

\section{Conflicts of interest. None.}

1. Global Initiative for Asthma. Chapter 4: Management of worsening asthma and exacerbations. In Global Strategy for Asthma Management and Prevention 2021. https://ginasthma.org/wp-content/ uploads/2021/05/GINA-Main-Report-2021-V2-WMS.pdf (accessed 10 June 2021).

2. Global Initiative for Asthma. Pocket guide for asthma management and prevention (for adults and children older than 5 years) 2021. https://ginasthma.org/wp-content/uploads/2021/05/GINA-PocketGuide-2021-V2-WMS.pdf (accessed 10 June 2021).

3. Irusen EM. The Global Initiative for Asthma 2019 recommendation for mild asthma - a critique. S Afr Fam Pract 2020;62(1):a5104. https://doi.org/10.4102/safp.v62i1.5104

4. Castillo JR, Peters SP, Busse WW. Asthma exacerbations: Pathogenesis, prevention and treatment. Castillo JR, Peters SP, Busse WW. Asthma exacerbations: Pathogenesis, prevention and
J Allergy Clin Immunol Pract 2017;5(4):918-927. https:///oi.org/10.1016/j.jaip.2017.05.001

5. O'Byrne PM, Jenkins C, Bateman ED. The paradoxes of asthma management: Time for a new approach? Eur Respir J 2017;50(3):1701103. https://doi.org/10.1183/13993003.01103-2017

6. O'Byrne PM, FitzGerald JM, Bateman ED, et al. Inhaled combined budesonide-formoterol as needed in mild asthma. N Engl J Med 2018;378(20):1865-1876. https://doi.org/10.1056/NEJMoal71527

7. Bateman ED, Reddel HK, Barnes PJ, et al. As-needed budesonide-formoterol versus maintenance budesonide in mild asthma. N Engl J Med 2018;378(20):1877-1887. https://doi.org/10.1056/ NEJMoa1715275

8. Reddel HK, FitzGerald JM, Bateman ED, et al. GINA 2019: A fundamental change in asthma management: Treatment of asthma with short-acting bronchodilators alone is no longer recommended for adults and adolescents. Eur Respir J 2019;53(6):6. https://doi.org/10.1183/13993003.01046-2019

9. Cloutier MM Baptist AP, Blake KV et al. Expert Panel Working Group of the National Heart,

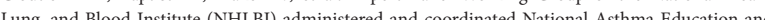
Prevention Program Coordinating Committee (NALFPCC). 2020 focused updates to the asthma management guidelines: A report from the National Ashma Eduction and Prevention Program Coordinating Committee Expert Panel Working Group. J Allergy Clin Immunol 2020;146(6):1217 1270. https://doi.org/10.1016/j.jaci.2020.10.003

10. Barnes PJ, Szefler SJ, Reddel HK, Chipps BE. Symptoms and perception of airway obstruction in asthmatic patients: Clinical implications for use of reliever medications. J Allergy Clin Immuno 2019;144(5):1180-1186. https://doi.org/10.1016/j.jaci.2019.06.040

11. McKeever T, Mortimer K, Wilson A, et al. Quadrupling inhaled glucocorticoid dose to abort asthma exacerbations. N Engl J Med 2018;378(10):902-910. https://doi.org/10.1056/NEJMoa1714257

12. Connett GJ, Lenney W. Use of pulse oximetry in the hospital management of acute asthma in childhood. Pediatr Pulmonol 1993;15(6):345-349. http://doi.org/10.1002/ppul.1950150606

13. Geelhoed GC, Landau LI, Le Souëf PN. Evaluation of $\mathrm{SaO} 2$ as a predictor of outcome in 280 children presenting with acute asthma. Ann Emerg Med 1994;23(6):1236-1241. http://doi.org/10.1016/S01960644(94)70347-7

14. Wright RO, Santucci KA, Jay GD, Steele DW. Evaluation of pre- and post-treatment pulse oximetry in acute childhood asthma. Acad Emerg Med 1997;4(2):114-117. http://doi.org/10.1111/j.1553-2712.1997. acute child
15. Chang AB, Clark R, Sloots TP, et al. A 5- versus 3-day course of oral corticosteroids for children with asthma exacerbations who are not hospitalised: A randomised controlled trial. Med J Aust 2008;189(6):306-310. https://doi.org/10.5694/j.1326-5377.2008.tb02046.x

16. Levin ME, Ansotegui IJ, Bernstein J, et al. Acute asthma management during SARS-CoV2 pandemic 2020. World Allerg Org J 2020;13(5):100125. http://doi.org/10.1016/j.waojou.2020.100125

17. Kling S, Zar HJ, Levin ME, et al. Guidelines for the management of acute asthma in children: 2013 update. S Afr Med J 2013;103(3):199-207. https://doi.org/10.7196/SAMJ.6658

8. Chien JW, Ciufo R, Novak R, et al. Uncontrolled oxygen administration and respiratory failure in acute asthma. Chest 2000;117(3):728-733. https://doi.org/10.1378/chest.117.3.728

19. Rodrigo GJ, Rodriquez Verde M, Peregalli V, Rodrigo C. Effects of short-term $28 \%$ and $100 \%$ oxygen on $\mathrm{PaCO} 2$ and peak expiratory flow rate in acute asthma: A randomized trial. Chest 2003;124(4):13121317. https://doi.org/10.1378/chest.124.4.1312

20. Perrin $\mathrm{K}$, Wijesinghe $\mathrm{M}$, Healy B, et al. Randomised controlled trial of high concentration versus titrated oxygen therapy in severe exacerbations of asthma. Thorax 2011;66(11):937-941. https://doi. org/10.1136/thx.2010.155259

21. Patel B, Khine H, Shah A, et al. Randomized clinical trial of high concentration versus titrated oxygen use in pediatric asthma. Pediatr Pulmonol 2019:54(7):970-976. https://doi.org/10.1002/ ppul.24329P

22. Iramain R, Castro-Rodrigues JA, Jara A, et al. Salbutamol and ipratropium by inhaler is superior to nebulizer in children with severe acute asthma exacerbation: Randomized clinical trial. Pediatr Pulmonol 2019;54(4):372-377. https://doi.org/10.1002/ppul.24244

23. Hui DS, Chow BK, Chu LC, et al. Exhaled air and aerosolized droplet dispersion during application of a jet nebulizer. Chest 2009;135(3):648-654. https://doi.org/10.1378/chest.08-1998

24. Plotnick LH, Ducharme FM. Acute asthma in children and adolescents: Should inhaled anticholinergics be added to beta(2)-agonists? Am J Respir Med 2003;2(2):109-115. https://doi. org/10.1007/BF03256642

25. Teoh L, Cates CJ, Hurwitz M, Acworth JP, van Asperen P, Chang AB. Anticholinergic therapy for acute asthma in children. Cochrane Database Syst Rev 2012;4:CD003797. http://doi.org/10.1002/14651858. CD003797.pub2

26. Vézina K, Chauhan BF, Ducharme FM. Inhaled anticholinergics and short-acting beta2-agonists versus short-acting beta2-agonists alone for children with acute asthma in hospital. Cochrane Database Syst Rev 2014;7:CD010283. https://doi.org/10.1002/14651858.CD010283.pub2

27. Castro-Rodriguez JA, Rodrigo GJ, Rodriguez-Martinez CE. Principal findings of systematic reviews of acute asthma treatment in childhood. J Asthma 2015;52(10):1038-1045. https://doi.org/10.3109/0 2770903.2015.1033725

28. Cheuk DK, Chau TC, Lee SL. A meta-analysis on intravenous magnesium sulphate for treating acute asthma. Arch Dis Child 2005;90(1):74-77. http://doi.org/10.1136/adc.2004.050005

29. Griffiths B, Kew KM. Intravenous magnesium sulfate for treating children with acute asthma in the emergency department. Cochrane Database Syst Rev 2016;4:CD011050. https://doi. org/10.1002/14651858.CD011050.pub2

30. Knightly R, Milan SJ, Hughes R, et al. Inhaled magnesium sulfate in the treatment of acute asthma. Cochrane Database Syst Rev 2017;11: CD003898.. https://doi.org/10.1002/14651858.CD003898.pub6

31. Watts $\mathrm{K}$, Chavasse RJPG. Leukotriene receptor antagonists in addition to usual care for acute asthma in adults and children. Cochrane Database Syst Rev 2012;5:CD006100. https://doi.org/10.1002/14651858. CD006100.pub2

Accepted 2 June 2021 